Revista de Economia Política, vol. 32, no 2 (127), pp. 282-304, abril-junho/2012

\title{
Metas de inflação, regra de Taylor e neutralidade da moeda: uma crítica pós-keynesiana
}

\author{
MARIANA DE LOURDES MOREIRA LOPES \\ MARIA DE LOURDES ROLLEMBERG MOLLO \\ FABIANO SILVIO COLBANO*
}

Inflation targeting, Taylor rule and money neutrality: a post-Keynesian critic. This paper critically discusses the inflation targeting regime proposed by orthodox economists, in particular the Taylor Rule. The article describes how the Taylor Rule assumes the argument of money neutrality inherited from the Quantitative Theory of Money. It discusses critically the ways of operation of the rule, and the negative impacts of the interest rate over the potential output. In this sense, the article shows the possible vicious circles of the monetary policy when money is not neutral, as is the case for post-keynesian economists. The relation of interest rates, potential output and the output gap is illustrated in some estimates using the methodology of Vector Auto-Regressive in the Brazilian case.

Keywords: quantitative theory of money; Taylor rule; potential output; postkeynesian critic; output gap.

JEL Classification: E12; E52.

\section{INTRODUÇÃO}

O objetivo deste artigo é discutir o sistema de metas inflacionárias do ponto de vista heterodoxo pós-keynesiano. Mais particularmente, trata-se de, em primeiro lugar, retomar o debate sobre a neutralidade, ou não neutralidade da moeda, procurando mostrar que o regime de metas inflacionárias e, em particular, a regra

\footnotetext{
* Respectivamente, Doutora em Economia pela Universidade de Brasília. E-mail: mariana.lopes@fazenda.gov.br; Professora do Departamento de Economia da Universidade de Brasília. E-mail: mlmollo@ unb.br; Mestre em Teoria Econômica pelo IPE/USP. E-mail: fabiano.colbano@fazenda.gov.br. Submetido: 7/Abril/2010, Aprovado: 10/Maio/2011.
} 
de Taylor, supõem a neutralidade da moeda, o que os torna discutíveis do ponto de vista pós-keynesiano.

Como destaca Modenesi (2008), essa não é uma posição consensual dentro da heterodoxia, uma vez que alguns pós-keynesianos procuram adaptar ou compatibilizar o sistema de metas inflacionárias com a teoria monetária pós-keynesiana, como é o caso de Setterfield (2006) e Palley (2006). Mas é ampla a crítica ao chamado novo consenso de política monetária que, como veremos, adota o regime de metas inflacionárias como instrumento de estabilização de preços preferido.

O próprio Setterfield (2005) chama a atenção que o novo consenso em política monetária, ao adotar o sistema de metas inflacionárias, opta pela taxa de juros como instrumento privilegiado de política, mas isso se faz comprometendo a robustez analítica da estabilidade do equilíbrio macroeconômico. Fitzgerald (2005) critica os efeitos da meta inflacionária na utilização de capacidade e na competitividade externa das economias emergentes.

Quanto à crítica pós-keynesiana ao regime de metas inflacionárias para o caso do Brasil, vem sendo feita de várias formas. O trabalho de Arestis et al. (2009), por exemplo, mostra que o regime de metas é discutível porque supõe inflação de demanda, enquanto no Brasil ela é de custos, provocada por choques de oferta e inércia resultante de preços administrados.

Resende e Lima (2007), e Pelicioni e Resende (2009), por sua vez, estudando os casos de dezessete países entre os quais o Brasil, criticam o suposto de neutralidade da moeda e o uso do regime de metas inflacionárias, mostrando o impacto dessa política monetária sobre a economia real, por meio da relação negativa entre a política monetária restritiva e o investimento. Segundo os autores, o uso do regime conduz a que, em situação de inflação alta observada, a expectativa de contração monetária, em função do regime de metas inflacionárias em vigor, leve à queda da rentabilidade esperada para o investimento, desestimulando o investimento corrente.

Embora a crítica ao combate inflacionário via sistema de metas e aos impactos de juros sobre o investimento já tenha sido feita, conforme mencionado, apresentamos aqui dois testes econométricos usando modelo VAR para ilustrar os efeitos negativos da taxa de juros sobre o produto potencial, indicador da capacidade produtiva da economia, e a influência positiva que pode ter sobre o hiato de produto. Assim fazendo, mostramos como são discutíveis os argumentos de neutralidade da moeda e o uso da regra de Taylor para conduzir a política monetária.

Para isso, analisa-se, na segunda seção, após esta introdução, o sistemas de metas inflacionárias e a regra de Taylor, destacando o argumento de neutralidade. Também nessa seção são destacadas as diferenças entre as correntes teóricas que propõem o regime de metas e a heterodoxia pós-keynesiana, que o critica. Em segundo lugar, na terceira seção, o artigo busca mostrar como, no caso brasileiro, o uso desse regime pode ser contraproducente. No quarta seção, das considerações finais, são sumariados os principais argumentos e conclusões do artigo. 


\section{O REGIME DE METAS DE INFLAÇÃO E A REGRA DE TAYLOR}

\section{O regime de metas inflacionárias e o novo consenso em política monetária}

O regime de metas inflacionárias usado de forma muito ampla na atualidade é derivado teoricamente das discussões que permearam o debate dos anos $1970 \mathrm{e}$ 1980 sobre regras versus discricionariedade (Kydland e Prescott, 1977; Barro e Gordon, 1983; Taylor, 1993), após as expectativas racionais (Lucas, 1972; Sargent e Wallace, 1975) tornarem-se dominantes.

Tanto esse regime, quanto a regra de Taylor com a qual é operado são peças fundamentais do chamado novo consenso de política monetária (Mishkin, 2000, 2001; Woodford, 2001). A ideia de fundamentar microeconomicamente os modelos macroeconômicos de equilíbrio geral, embora concebendo uma gama de friç̧ões e rigidezes no processo de ajustamento, assim como a introdução de expectativas racionais para explicar que os efeitos de variáveis monetárias sobre a economia real são apenas transitórios (moeda neutra a longo prazo), são marcos desse consenso que une novos clássicos e novos keynesianos. A essas ideias, Woodford (2008) acrescenta algumas outras para melhor defini-lo. Para ele, embora a política monetária não possa ser considerada irrelevante para explicar flutuações, as suas fontes mais importantes são reais. A política monetária, por sua vez, é relevante para determinar e controlar o nível de preços, cujo crescimento tem raízes monetárias. A política monetária deve ser então usada apenas para isso, já que não tem efeito duradouro sobre a economia real (moeda neutra).

Essa ideia de controle da moeda e da inflação pelas autoridades monetárias (moeda exógena) e o papel meramente transitório da política monetária sobre a economia real (moeda neutra) são herdados da Teoria Quantitativa da Moeda (TQM). Dela é também possível derivar as prescrições de política mais adequadas, que são o uso de regras e ou de práticas de compromisso dos governos com a condução ortodoxa da política monetária (Cukierman, 1994; Walsh, 1995; Mishkin, 2000), evitando o viés inflacionário que lhes é próprio (Kydland e Prescott, 1977).

Apesar de derivada da Teoria Quantitativa da Moeda a meta inflacionária é uma regra operada por meio da taxa de juros, e não por meio de controle de agregados monetários. Isso é resultado do reconhecimento teórico de que a velocidade de circulação da moeda, ao invés de estável ou mesmo previsível, conforme Friedman (1956) é, ao contrário, instável, o que dificulta a intervenção das autoridades monetárias sobre os agregados monetários para o controle do nível geral de preços. Essa evolução na concepção ortodoxa pode ser mais bem percebida quando se compara o trabalho de Laidler (1971), dando conta de resultados econométricos favoráveis à estabilidade da demanda de moeda e, então, da sua velocidade de circulação, com os dos trabalhos de Bordo e Jonung $(1981,1987)$, negando tal estabilidade, ao constatar que a velocidade de circulação da moeda mostrava uma forma de U, aumentando com as inovações financeiras após a Segunda Guerra Mundial. Tal percepção levou, assim, ao longo do tempo, ao abandono do monetarismo friedmaniano, que prescrevia o controle de preços intervindo sobre os 
agregados monetários, passando-se a intervir sobre a taxa de juros como instrumento de política monetária para controle da inflação ${ }^{1}$.

Essa mudança é apontada como uma vitória keynesiana sobre os monetaristas como Friedman. Contudo, o regime de metas é operado com quase nenhuma consideração para os impactos sobre fatores reais ou outros objetivos de política econômica diferentes do controle de preços, preocupação constante na obra final de Keynes, o que explica a crítica pós-keynesiana ao novo consenso de política monetária. Conforme Arestis e Sawyer (2005, p. 10), descrevendo este novo consenso "in the long run the inflation rate is the only macroeconomic variable that monetary policy can affect. Monetary policy cannot affect economic activity, for example, output, employment and so on, in the long run". Mesmo quando esse regime considera a taxa de crescimento do produto, o faz buscando evitar que o crescimento do mesmo imponha pressões inflacionárias ${ }^{2}$. Assim, a chamada discricionariedade restrita permitida na regra de Taylor, segundo Bernanke et al. (1999), relaciona-se apenas com algum grau de inflação admitido e não com impactos duradouros da política monetária sobre a economia real ou sobre a capacidade produtiva da economia.

Isso reflete exatamente a ideia de neutralidade da moeda. É o que ressalta também Palley (2006), dizendo que entre os princípios que norteiam o novo consenso de política monetária está a aceitação da neutralidade da política monetária no longo prazo mesmo quando se admite a não neutralidade no curto prazo. Concebem a existência de uma curva de Phillips a ser explorada no curto prazo, em função da rigidez de preços e salários. No entanto, no longo prazo, entendido como o período em que os preços e salários são flexíveis, admite-se a existência de uma curva de Phillips vertical, ou seja, não se espera impacto duradouro de impulsões monetárias ou da política monetária sobre a economia real.

Taylor (1993) propôs a regra que se tornou referência para operar o regime de metas inflacionárias, em artigo citado na literatura, pela utilização de uma função de reação para o comportamento das taxas internas de juros nos EUA no período entre 1987 e 1992.

De acordo com o autor, o comportamento das taxas de juros nos EUA poderia ser muito bem representado por uma relação linear com a taxa de inflação $\left(\pi_{t}\right)$, uma

\footnotetext{
${ }^{1}$ A dificuldade de operar a política monetária por meio de agregados monetários também foi analisada pelos keynesianos ao longo do tempo, em particular, mais recentemente, pelos chamados horizontalistas (Moore, 1988; Lavoie, 1992, entre outros), que concebem a taxa de juros como o instrumento adequado para operar uma política monetária efetiva Para uma comparação entre pós-keynesianos horizontalistas e estruturalistas, mostrando pontos de encontro dos primeiros com a ortodoxia, ver o artigo de Mollo (1999).

${ }^{2}$ Em muitas ocasiões o Banco Central do Brasil justificou o aumento das taxas de juros, nas atas do COPOM (Comitê de Política Monetária), com base na diferença entre o produto efetivo e o produto potencial, mostrando maior preocupação com o controle inflacionário do que com os problemas do crescimento. É o que indica a inércia observada no movimento de baixa da taxa de juros, mesmo quando a inflação e o produto evoluem da maneira desejada (Modenese, 2008).
} 
taxa de juros de equilíbrio $\left(\mathrm{r}^{*}\right)$ mais uma soma ponderada entre dois desvios: a diferença entre taxa de inflação (medida pelo deflator do PIB) e a meta de inflação e o desvio percentual entre o PIB efetivo (observado) e o PIB potencial. Dessa forma, a Regra de Taylor depende de duas variáveis exógenas ao modelo: a meta de inflação e o PIB potencial. A relação destas variáveis pode ser mais bem visualizada da seguinte forma:

$$
i_{t}=\pi_{t}+r^{*}+\alpha\left(\pi_{t}-\pi^{*}\right)+\beta\left(\frac{y_{\text {efetivo }}-y_{\text {potencial }}}{y_{\text {potencial }}}\right)
$$

onde,

$\mathrm{i}_{\mathrm{t}}=$ taxa básica de juros nominais;

$\mathrm{y}_{\text {potencial }}=$ capacidade produtiva da economia;

$\mathrm{y}_{\text {efetivo }}=$ produto corrente;

$\mathrm{r}^{*}=$ taxa real de juros de equilíbrio;

$\pi_{\mathrm{t}}=$ taxa média da inflação dos últimos quatro trimestres (deflator do PIB);

$\pi^{*}=$ meta da taxa de inflação; e

$$
\left(\frac{y_{\text {efetivo }}-y_{\text {potencial }}}{y_{\text {potencial }}}\right)=\text { hiato do produto em termos percentuais }
$$

Ele não estimou esta equação econometricamente, assumindo apenas que os pesos utilizados pelo FED seriam de 1.5, para o desvio da inflação, e de 0,5 , para o desvio do PIB $^{3}$. Assim, se, por exemplo, a inflação fosse um ponto percentual acima da meta, o FED deveria elevar em $1,5 \%$ as taxas de juros. Como não realizou nenhuma estimação dos coeficientes, o autor assume uma taxa de juros e uma meta de inflação de equilíbrio de $2 \%$. Esta representação apresentou desempenho muito interessante, tendo um grau de ajuste muito bom em relação ao período analisado, entre 1970 e 1998.

A relação entre a regra de Taylor e a TQM é afirmada pelo próprio Taylor (1998, p. 9), quando diz: "The policy rule is, of course, quite different from the quantity equation of money, but it is closely connected to the quantity equation. In fact it can be easily derived from the quantity equation". Conectada com a TQM, carrega em si o argumento da neutralidade da moeda presente na primeira. De fato, isso pode ser facilmente percebido a partir de dois pontos principais: (i) o diagnóstico de inflação é sempre de demanda nominal. (ii) o produto potencial (que nada mais é do que uma proxy da capacidade produtiva da economia) é suposto invariável a movimentos da taxa de juros. Vejamos melhor estes dois pontos.

Observando a regra de Taylor (1993, p. 200) em sua versão tradicional, conforme a equação (1), vemos que a taxa de juros reage ao desvio da inflação $(\pi)$ em

\footnotetext{
${ }^{3}$ Conforme Galí (2008), Taylor baseou-se em especificação anualizada de inflação e taxa de juros.
} 
relação à meta $\left(\pi^{*}\right)$ e ao desvio do produto efetivo $\left(\mathrm{y}_{\text {efetivo }}\right)$ em relação ao produto potencial $\left(\mathrm{y}_{\text {potencial }}\right)$. Em outras palavras, implica uma elevação (redução) da taxa de juros quando a inflação se encontra acima (abaixo) da meta e, de forma análoga, indica que no caso de diferença positiva (negativa) entre o crescimento do PIB e do que se considera o seu potencial deve haver um aumento (declínio) na taxa de juros, de forma a inibir o crescimento do produto ou da demanda, para que ele se ajuste à capacidade plena da economia ou ao nível de pleno emprego dos fatores de produção.

$\mathrm{Na}$ concepção ortodoxa, a inflação é sempre de demanda e um fenômeno monetário, ocasionado pela demanda excessivamente aquecida por impulsões monetárias em relação à capacidade de oferta da economia ou em relação ao nível de pleno emprego. Uma vez assumida a neutralidade da moeda, impulsões monetárias como as provocados por política monetária expansionista levam apenas ao aumento da inflação, uma vez que a moeda é neutra e não pode afetar de forma permanente as variáveis reais da economia, ou a oferta. Daí por que variações na taxa de juros não podem afetar, na regra de Taylor, o produto potencial, ou a capacidade produtiva da economia, que é suposto estar no seu nível de pleno emprego (Mollo, 2004). Neste tipo de regime monetário, o hiato do produto é visto como o principal referencial para a existência de pressões de demanda. Mudar a capacidade produtiva de forma duradoura requer mudanças nas variáveis reais, preferências e tecnologias. Sem essas, ou a partir de impulsões monetárias, o único resultado permanente, segundo essa concepção econômica, é o aumento do nível geral de preços.

Assim, para a ortodoxia, quando o produto efetivo ultrapassa o produto potencial, surge o hiato de produto, conforme a equação $1 \mathrm{e}$, se a partir daí a taxa de crescimento do produto efetivo for maior que a do produto potencial, o hiato cresce, o inverso ocorrendo quando a taxa de crescimento do produto efetivo for menor que a do produto potencial. Quando o hiato aparece ou cresce, espera-se que a inflação aumente. A regra de Taylor prega então o aumento da taxa de juros, para diminuir aumentos da produção e da demanda nominal e, consequentemente, a inflação. Ao contrário, quando o hiato do produto se reduz ou é eliminado, a ortodoxia supõe que o produto efetivo se acomoda melhor à capacidade produtiva (produto potencial), razão pela qual a taxa de juros pode cair, sem que haja pressão inflacionária por aumento de demanda nominal sem contrapartida de aumento de oferta.

\section{A crítica pós-keynesiana ao regime de metas e à regra de Taylor}

Se o hiato do produto é definido como aquele que ocorre quando o produto efetivo supera o produto potencial, ele pode ser reduzido, para a ortodoxia, com taxas de juros mais elevadas, porque o produto efetivo cai relativamente ao produto potencial que é suposto não ser afetado dada a neutralidade da moeda. Quando a taxa de juros sobe e inibe, de fato, a produção corrente (ou produto efetivo) e, com a queda da demanda agregada que isso representa, impõe pressão deflacionária. Além disso, inibe a inflação porque leva à desova de estoques. Isso é o pre- 
visto pela ortodoxia. O que não é previsto, porém, em virtude do suposto de pleno emprego dos fatores de produção, que não pode ser alterado por impulsões monetárias porque para eles a moeda é neutra, é que o produto potencial também pode cair ao longo do tempo, ou crescer menos que o produto efetivo, quando a taxa de juros sobe. Se isso ocorre, o aumento do hiato do produto não deveria ser tratado com aumento da taxa de juros porque, respondendo à regra de Taylor, os juros serão, nesse caso, resistentes à queda, porque a queda do produto potencial dificultará a queda do hiato de produto. Tende-se, assim, a prejudicar desnecessariamente o investimento e o crescimento da produção e do emprego, o que implica elevado custo social.

Para os pós-keynesianos, a moeda, ao invés de neutra, tem enorme importância para a realização dos investimentos. Por um lado, é a disposição do sistema bancário de se tornar ilíquido (Keynes, 1937, a, b, e c) que garante que o investidor conseguirá condições de empréstimos apropriadas, uma vez confrontadas com a rentabilidade esperada do capital, para concretizar sua decisão de investimento. Trata-se, segundo Keynes, do motivo finance de demanda de moeda. Por outro lado, a consolidação ou o funding do investimento depende da preferência pela liquidez dos poupadores. Só se ela for reduzida é possível contar com empréstimos de longa maturação para converter as dívidas de curto prazo, tomadas nos primeiros momentos do investimento, em dívidas compatíveis com seus prazos de maturação. Só, portanto, condições monetárias favoráveis, em termos de reduzida preferência pela liquidez dos bancos e dos poupadores, garantem o crescimento do investimento e então da produção, da capacidade de produção e do emprego na economia.

Para a heterodoxia pós-keynesiana, portanto, a operacionalização do regime de metas, ao aumentar os juros, reduz tanto o produto efetivo como o produto potencial, ameaçando a produção, a capacidade produtiva e o emprego.

No caso do Brasil, conforme destaca Hermann (2003), o aumento da taxa de juros básica estimula a preferência pela liquidez dos poupadores, atraindo recursos para títulos públicos e impedindo o funding dos investimentos de média e longa maturação. Isso ocorre porque quando as taxas de juros dos títulos de curto prazo são altas, a taxa para atrair poupanças para títulos de médio e longo prazos para consolidar os investimentos (funding) tem que ser mais alta ainda, porque precisa conter o prêmio de liquidez. Essas taxas de juros não conseguem, por outro lado, ser compensadas pelas eficiências marginais dos capitais para muitos investidores, e o investimento é, por essa razão, inibido.

O aumento da taxa básica de juros da economia pelo Banco Central, além disso, serve de referência para as demais taxas de juros, dentro da chamada "hierarquia" das taxas de juros. Assim, quando a taxa de juros básica da economia aumenta, as taxas de juros dos empréstimos bancários também tendem a se elevar, prejudicando o papel potencializador sobre a produção que o crédito tem na percepção pós-keynesiana.

Ao aumentar a taxa de juros com o objetivo de reduzir o hiato do produto, o Banco Central pode não ter sucesso porque a capacidade produtiva da economia 
cai ou cresce pouco relativamente ao crescimento do produto efetivo. Isso pode levar a economia a conviver com constantes taxas de crescimento abaixo daquelas desejadas pela sociedade, devido ao ambiente desfavorável criado para as decisões de investimento. É o que concluem para o caso brasileiro Arestis et al. (2009).

Sicsú (2003, pp. 30-31) argumenta que, particularmente no caso brasileiro, diante de qualquer suspeita de elevação do nível de preços, segundo a regra ortodoxa de estabilização de preços, eleva-se a taxa de juros, mas não há dúvida de que tal política também reduz o nível de investimentos privados (Resende e Lima, 2007; Pelicioni e Resende, 2009) e, pelo efeito multiplicador, resfria toda a economia e aumenta o desemprego.

Outras críticas heterodoxas relevantes dizem respeito à constatação de que a inflação não depende exclusivamente de fatores de demanda, como supõe a regra de Taylor, dependendo também de fatores ligados à oferta; de quão efetiva é a política monetária, mesmo para controle de demanda; e de remédios outros para a inflação, uma vez que ela é sobretudo de custos (Arestis e Sawyer, 2005).

Para Sicsú (2002), autores pós-keynesianos — como Davidson (1994) e Wray (1997) — reconhecem que a utilização da taxa de juros pode ser eficaz para controlar a inflação, mas, ainda assim, não recomendam sua utilização devido aos impactos que uma elevação da taxa de juros causa sobre o desemprego. A ideia pós-keynesiana, em oposição à regra convencional de disciplina da política monetária e de busca do controle do nível de preços, é que uma elevação da taxa de juros atacaria os sintomas da inflação e não as suas causas. Tal elevação dificultaria a passagem de um aumento de custos aos preços (o sintoma), mas não resolveria o problema da elevação de custos (a causa). A proposição pós-keynesiana é que existem vários tipos de inflação e para cada tipo deve ser utilizado um instrumento anti-inflacionário diferente, sempre buscando atacar a(s) causa(s) da inflação.

Mesmo que aumentos na taxa de juros inibam a demanda e a produção, ao afetarem negativamente a capacidade produtiva ou o seu crescimento, têm menor efeito sobre a inflação do que esperado, e submetem a economia a um custo social elevado em termos de desemprego.

\section{As discussões sobre o produto potencial}

O cálculo do produto potencial é feito com base em técnicas estatísticas de suavização, ou com base em modelos de função de produção que contemplam variáveis passadas, independentes dos estímulos monetários que a manipulação da taxa de juros oferece, ratificando, de outra forma, o argumento de neutralidade da moeda. É o caso das técnicas de tendência linear e o filtro Hodrick e Prescott (HP). $\mathrm{O}$ método da tendência linear consiste basicamente em extrair uma tendência de uma série de dados (produção industrial, por exemplo) e a tendência extraída, baseada no passado, seria então considerada como produto potencial. Por resíduo, encontra-se o hiato (Souza Júnior, 2005). O filtro HP, por sua vez, consiste em uma simples operação linear sobre a série em análise, definindo a tendência de longo 
prazo como uma média ponderada da série, cabendo ao analista definir quão "suave" deve ser a taxa de variação desta tendência (IEDI, 2006).

Vários estudos criticam a noção de produto potencial (Woodford, 2001, a; Kanczuk, 2004), propondo alternativas de cálculo para resolver os problemas apontados. Nenhuma delas, porém, resolve o problema aqui analisado. Ou seja, em todos os casos mantêm o argumento de neutralidade da moeda, não assumindo a relação negativa entre o aumento a taxa de juros e o produto potencial. É o caso, por exemplo, das propostas de relacionar o produto da economia com os fatores disponíveis, em particular com o estoque de capital, através de uma função de produção. A estimação de uma função de produção não é, porém, isenta de problemas. Por um lado, existem todas as questões relacionadas com a medição do estoque de capital, que levam a uma medição indireta via acumulação de fluxos de investimento. Mas, sobretudo, a estimação do produto potencial a partir da estimação de uma função de produção exige que se calcule previamente o volume "natural" de emprego. Ora, estimar este emprego natural a partir do emprego observado, apenas transforma o problema (de estimação do produto potencial) num outro problema de natureza similar (de estimação do volume natural de emprego), em todos os casos supondo que impulsões monetárias são neutras, ou seja, não os afetam de forma duradoura.

Woodford $(2001$, a) critica métodos de suavização para o produto (como o filtro HP), uma vez que grande variedade de choques reais afeta o produto potencial. Estes choques incluem choques tecnológicos, mudanças na oferta de trabalho, variações no consumo do governo, e variações na produtividade das oportunidades de investimento disponíveis, e não há nenhuma razão para assumir que todos esses fatores seguem tendências suaves. Observa-se, porém, que as críticas são ortodoxas, uma vez que não se trabalha com a hipótese de choques monetários podendo afetar o produto potencial, mas apenas choques reais.

$\mathrm{Na}$ mesma linha de Woodford, Kanczuk (2004) também critica do ponto de vista econométrico a ausência de impactos sobre a oferta que criticamos aqui, mas usando argumentos ortodoxos. Ele argumenta que por não considerar a presença de choques reais sobre a oferta, os modelos estruturais baseados na regra de Taylor (1993) estão especificados incorretamente. Segundo ele, em contraste com estes modelos amparados na regra de Taylor, com os modelos de RBC (Real Business Cycle) é possível separar os efeitos dos choques de oferta e demanda além de ser (potencialmente) robusto à Crítica de Lucas.

Observe-se nessas críticas que, ou temos apenas fatores reais concebidos para afetar o produto potencial, ou o calculamos baseado no passado, calculando o produto potencial como uma média dos valores observados para trás. Em todos os casos a gestão da taxa de juros e as decisões de investimento que dela dependem não afetam o potencial produtivo da economia, mantendo o argumento de neutralidade da moeda ${ }^{4}$.

De forma a compreender melhor o problema da regra de Taylor no processo

\footnotetext{
${ }^{4}$ Outras críticas ortodoxas à regra de Taylor não foram incorporadas aqui por não estarem relacionadas com a neutralidade/não neutralidade da moeda. É o caso, por exemplo, de Svensson (2003).
} 
de estabilização brasileiro, faremos a seguir alguns exercícios para verificar o impacto da taxa de juros sobre o produto potencial. Com esses exercícios, procuraremos ilustrar nossos argumentos.

\section{REGRA DE TAYLOR, TAXA DE JUROS E PRODUTO POTENCIAL NO BRASIL}

\section{A hipótese e o modelo}

Enquanto os trabalhos de Resende e Lima (2007) e Pelicioni e Resende (2009) mostram o caráter contraproducente do regime de metas inflacionárias para o investimento, tornando discutível a neutralidade da moeda suposta pela economia ortodoxa, aqui mostraremos como a regra de Taylor, ao supor tal neutralidade, pode inibir o crescimento da capacidade produtiva da economia, tornando discutível a forma usada para o controle da inflação.

O uso da regra de Taylor torna-se discutível porque o aumento da taxa de juros, ao afetar também o produto potencial além do efetivo, pode manter o hiato de produto estável, resistente a queda ou até levá-lo a crescer, sinalizando equivocadamente para novos aumentos da taxa de juros. Ou seja, a regra de Taylor levaria a uma situação de resistência da taxa de juros a baixar, com todos os inconvenientes de custo social elevado em termos de queda do crescimento e do emprego.

Com o propósito de investigar as relações entre as variáveis envolvidas na regra de Taylor - isto é, taxa de juros, inflação, produto efetivo, produto potencial e hiato de produto - utilizaremos a metodologia dos Vetores Auto-Regressivos (VAR), comumente usados para a estimação de sistemas inter-relacionados de séries temporais e análise de impactos dinâmicos de choques. O VAR nada mais é que um conjunto de equações em que as variáveis endógenas são colocadas como funções de suas próprias defasagens. Uma vez que se garanta a estacionariedade destas variáveis endógenas (através de testes de raiz unitária), as estimativas dos parâmetros do modelo $V_{A R}^{5}$ podem ser consistentemente estimados através do método de Mínimos Quadrados Ordinários (MQO) (Stock \& Watson, 2001).

$\mathrm{O}$ uso de tal metodologia é uma forma de se estimar relações dinâmicas entre variáveis endógenas sem a imposição, a priori, de fortes restrições. Uma vantagem da abordagem é não ter que decidir quais variáveis são endógenas ou exógenas no momento da estimação, pois todas as variáveis são tomadas como endógenas (Davidson \& Mackinnon, 1993).

\footnotetext{
${ }^{5} \mathrm{O}$ modelo VAR estimado é conhecido como "modelo VAR na forma reduzida". Este modelo deriva de um modelo mais geral conhecido como "modelo VAR estrutural". A priori, como o modelo VAR na forma reduzida possui menos parâmetros que o modelo VAR estrutural, não seria possível a identificação exata deste segundo modelo através das estimativas dos parâmetros do primeiro modelo. Neste caso, dizemos que o modelo VAR estrutural é superidentificado, e sua identificação exata só é possível quando se impõe restrições sobre um subgrupo de seus parâmetros estruturais.
} 
Conforme já mencionado, é preciso evitar o uso das definições de produto potencial que impliquem tomar como referência o passado, uma vez que, se a moeda não é neutra, ela pode estimular a produção e a capacidade de produção da economia, mudando a trajetória para o futuro, ou fazendo com que ele evolua diferentemente do que ocorreu no passado. Usamos aqui o produto potencial tal como definido por Feijó (2006), que propõe calcular os dados de capacidade produtiva, inexistentes nas estatísticas brasileiras, a partir dos dados disponíveis de utilização desta capacidade. A representação algébrica da medida de grau de utilização de capacidade instalada se expressa como $\mathrm{u}=\frac{Y}{Y^{\prime}}$, onde u é a taxa de utilização de capacidade, Y e Y* são respectivamente o produto corrente (efetivo) e o produto a plena capacidade (potencial). Nesse caso, calculamos a capacidade produtiva (produto potencial) não a partir de série pregressa, mas usando dados efetivos de sua utilização, conforme pesquisa realizada pela Confederação Nacional da Indústria, aplicados sobre a produção total efetiva. Como a pesquisa colhe dados industriais de utilização de capacidade, usamos os dados de produção industrial como proxy do produto efetivo. Mais particularmente, nesse último caso usamos o quantum da produção na indústria de transformação (IBGE/PIM-PF).

Com as proxys das variáveis produto efetivo e produto potencial definidas, podemos comparar os impactos da taxa de juros sobre a produção efetiva e sobre a produção potencial e, a partir daí, ilustrar nossa crítica à regra de Taylor.

Partimos, pois, das proxies abaixo:

Produção Industrial (PIND_EFETIVO): Produção industrial da indústria de transformação - quantum - índice dessazonalizado. (média $2002=100$ ), do Instituto Brasileiro de Geografia e Estatística, Pesquisa Industrial Mensal — Produção Física (IBGE/PIM-PF).

Nível de Utilização da Capacidade Instalada (NUCI): Utilização da capacidade instalada na indústria, dessazonalizado (\%), da Confederação Nacional da Indústria, Indicadores Industriais $(\mathrm{CNI})$.

Vale lembrar que o NUCI da indústria é o indicador utilizado para determinar a possibilidade de expansão da oferta de produtos industriais. Esse índice é um dos indicadores utilizado pelo Banco Central para definir sua política, ou a trajetória da taxa Selic: um NUCI mais alto pode indicar a incapacidade da indústria de suportar, com elevações de oferta, um projetado aumento de demanda.

No VAR que estimamos usamos estas variáveis e também as séries de SELIC e IPCA. Todas são de periodicidade mensal, de maio de 2000 a setembro de 2008. Começamos em 2000, no ano seguinte àquele em que o Brasil começou a operar com o sistema de metas inflacionárias, uma vez que o ano de 1999 representa uma quebra estrutural para a série de dados utilizada.

Seguindo os procedimentos para o teste ADF (Augmented Dickey-Fuller) apresentados em Enders (2004), realizamos o teste para verificar a estacionariedade das séries. Todas as séries estudadas se revelaram não estacionárias quando avaliadas no nível, mas eram estacionárias em primeira diferença. Ou seja, as séries se revelaram integradas de primeira ordem, como observado na Tabela 1. Assim, a análise empírica desenvolvida neste trabalho foi feita com variáveis em primeira diferença. 
O passo seguinte foi a seleção do melhor modelo VAR referente às variáveis já aqui destacadas. Para tanto, utilizou-se o procedimento-padrão de estimação “General-to-Specific Modeling”. Por este procedimento, inicia-se a modelagem por um modelo mais geral para, a partir daí, reduzirmos a um modelo mais parcimonioso. No caso do VAR, o modelo mais geral é aquele com mais defasagens e, a partir de então, passa-se a estimar modelos com menos defasagens até que se encontre aquele que seja ótimo. A otimalidade do número de defasagens do VAR é determinada pelos critérios de informação ${ }^{6}$. Além da parcimônia na modelagem, os critérios contribuem para que o modelo selecionado tenha resíduos sem a presença de autocorrelação.

Pela Tabela 2, vemos que um maior número de critérios (FPE e AIC) indica que o uso de quatro defasagens no modelo é o mais adequado e por isso optamos por este número na estimação do VAR.

Após a escolha do melhor modelo VAR e sua estimação, passamos agora à interpretação dos resultados do modelo por meio do teste de causalidade de Granger, da análise da decomposição da variância dos erros de previsão e das funções de impulso-resposta para cada variável considerada.

\section{Os resultados do modelo VAR}

\subsection{Testes sobre a influência da taxa de juros sobre o produto potencial e o produto efetivo}

Analisaremos abaixo os resultados do modelo VAR, detendo-nos naqueles que interessam mais particularmente a este artigo, quais sejam, os que verificam a influência da taxa de juros sobre o produto efetivo e o produto potencial.

a) IPCA

A estimação do modelo VAR, com a aplicação dos testes de causalidade de Granger ${ }^{7}$, da análise de decomposição da variância dos erros de previsão e das funções impulso-resposta indicou que a taxa de juros Selic, o principal instrumento utilizado pelo Banco Central para realizar política monetária, é capaz de influenciar a variação da inflação. Pela análise da decomposição da variância dos erros de previsão do IPCA (Tabela 4), vemos que a participação da Selic é proporcionalmente maior $(44,7 \%)$ que a participação do produto efetivo e do produto potencial,

\footnotetext{
${ }^{6}$ Os critérios de informação usados estão na Tabela 2: LR, FPE, AIC, SC e HQ. Na análise dos critérios individualmente, determina-se o número ótimo de defasagens do VAR tomando-se aquela defasagem que está associada ao menor valor do critério em questão. Quando se utilizam conjuntamente vários métodos de informação, a literatura recomenda que se escolha aquela defasagem que a maioria dos métodos aponta como sendo mais adequado.

${ }^{7}$ As hipóteses nulas, de ausência de causalidade do tipo Granger, são hipóteses de ausência de correlação temporal entre as variáveis analisadas e são geralmente rejeitadas com probabilidade inferiores a $10 \%$ (valor fixado nesta pesquisa).
} 
que são respectivamente de $1,16 \%$ e $5,67 \%$. Ou seja, a Selic reduz a inflação, mas produto potencial e produto efetivo não a afetam tanto por meio de pressões de demanda, apesar de também causarem, no sentido de Granger, o IPCA.

Observe-se aqui que o efeito dos juros reduzindo a inflação não é motivo de discordância entre os economistas. Todos concordam que, no limite, uma taxa de juros muito elevada, ao contrair muito a produção e reduzir a demanda, pode levar à queda de preços. O que se discorda é que isso se dê sem afetar a capacidade produtiva de forma significativa, como se supõe com o argumento de neutralidade da moeda. Analisaremos isso adiante.

Pela análise da função impulso-resposta (Figura 1 adiante), podemos observar que no início, ou seja, nos primeiros seis meses, a inflação sobe, e só depois cai. Esse é o chamado "lag de transmissão da política monetária". Vale ressaltar que o próprio Banco Central reconhece em seus estudos que o efeito máximo do lag de política monetária ocorre em um prazo de seis a nove meses.

\section{b) Produção Industrial (PIND_EFETIVO)}

Com relação ao produto efetivo, pelo teste de causalidade de Granger (Tabela $5)$ percebe-se que ele sofre influência da taxa de juros e do produto potencial. Rejeita-se, dada a probabilidade menor que $10 \%$ a hipótese nula, de que a Selic não causa no sentido Granger o produto efetivo, assim como se rejeita também que o produto potencial não cause o produto efetivo. A análise da decomposição da variância (Tabela 6) mostra que a taxa de juros Selic é importante para explicar o comportamento do produto efetivo, já que, após doze meses, a taxa de juros Selic é responsável por cerca de $8 \%$ da variância do erro de previsão do produto efetivo.

\section{c) Produto Potencial (POTENCIAL)}

No que se refere ao produto potencial, percebe-se, de acordo com o teste de causalidade de Granger (Tabela 7), que a taxa de juros causa, no sentido de Granger, o produto potencial, uma vez que o p-valor é bem menor que $10 \%$. Ou seja, o resultado do teste de causalidade de Granger não permite aceitar a neutralidade da moeda tal como aparece na regra de Taylor, que assume que mudanças na taxa de juros não afetam o produto potencial.

d) Taxa de Juros (SELIC)

A taxa de juros Selic sofre influência apenas do IPCA (Tabela 9). Isto reflete apenas o próprio funcionamento do regime de metas inflacionárias e da regra de Taylor, uma vez que essa taxa é a forma de operar esse instrumento de política monetária e responde, por isso, à evolução da própria inflação.

Complementamos nossas análises por meio das funções de impulso-resposta, e consideramos apenas choques na taxa de juros, importante para o tema central deste artigo, como operador da regra de Taylor. Na Figura 1, vemos impactos principalmente a curto prazo tanto sobre o produto efetivo como sobre o produto potencial. Os impactos sobre o produto efetivo são maiores que os sobre o produto potencial, mas há impactos negativos significativos sobre esse último, dando razão à nossa preocupação.

Quando observamos os efeitos acumulados de um choque na taxa de juros 
(Figura 2), vemos que seu efeito final é maior sobre o produto efetivo que sobre o produto potencial ${ }^{8}$. Entretanto, como ocorre também impacto sobre o produto potencial, isso pode implicar uma informação de hiato que seja lida de forma equivocada pelos que operam a política monetária. Ou seja, o hiato pode se mostrar resistente à queda, estimulando outro aumento de taxa de juros que, além de voltar a provocar problemas para o produto potencial, inibe desnecessariamente a produção corrente e o emprego.

De forma a melhorar a nossa percepção sobre essa questão, estimamos um novo VAR considerando agora outra variável, o hiato do produto, definido como (Produto Efetivo - Produto Potencial)/ Produto Potencial.

\subsection{Teste sobre a influência da taxa de juros sobre o hiato de produto}

Esse novo VAR contém as variáveis hiato, conforme já definido, IPCA e taxa de juros (Selic). Sendo assim, substituímos as variáveis produto efetivo e produto potencial pelo hiato do produto.

Assim como no VAR anterior, o primeiro passo da estimação foi realizar o teste ADF para verificar a estacionariedade da série, que revelou-se não estacionária quando avaliada no nível, mas estacionária em primeira diferença, conforme observado na Tabela 11.

Da mesma forma, o passo seguinte foi a seleção do melhor modelo VAR referente às variáveis mencionadas. Pela Tabela 12 a seguir, vemos que maior número de critérios (FPE e AIC) indica o uso de quatro defasagens no modelo.

Destacaremos aqui, tal como fizemos no teste anterior, os resultados mais relacionados com o tema central deste artigo, qual seja, o dos impactos da taxa de juros sobre o hiato de produto.

a) IPCA

Os resultados para o IPCA são os mesmos que os obtidos no teste anterior, ou seja, da mesma forma que o produto efetivo e o potencial afetavam a inflação, o hiato também afeta, e a Selic também afeta o IPCA.

b) Taxa de Juros

Quanto à taxa de juros, é resultado apenas do IPCA, que justamente é o indicador principal para que a política monetária aja por meio de mudanças na taxa de juros (Tabelas 15 e 16).

c) Hiato de Produto (Produto Efetivo - Produto Potencial) Produto Potencial

A controvérsia que nos interessa aqui investigar é justamente a influência da taxa de juros sobre o hiato. Se o aumento da taxa de juros afeta o produto efetivo tanto para ortodoxos como para heterodoxos, só para esses últimos ela afeta também

\footnotetext{
${ }^{8}$ Quanto mais distantes de zero estiverem os intervalos de confiança das respostas aos impulsos, mais significativos são considerados os impactos.
} 
o produto potencial. Assim, é de esperar, para os primeiros, que o hiato se reduza, por redução do produto efetivo, quando a taxa de juros aumenta, enquanto para os pós-keynesianos é possível que o hiato não caia, e que até aumente, por redução do produto potencial. $\mathrm{O}$ resultado da Tabela 17 não permite rejeitar a hipótese nula de que a taxa de juros não causa ou não afeta o hiato de produto, dando razão aos heterodoxos, embora a Tabela 18 mostre que o hiato varia com a Selic.

As funções de impulso-resposta, contidas nas Figuras 3 e 4, mostram o mesmo resultado, a falta de impacto significativo sobre o hiato de produto proveniente de um choque na taxa de juros ${ }^{9}$. Isso está relacionado com o impacto negativo que tem esse aumento sobre o produto potencial, compensando o impacto negativo que tem também sobre o produto efetivo. Torna-se possível, nessas circunstâncias, que a ausência do resultado esperado pela regra de Taylor com o aumento da taxa de juros sobre o hiato de produto sinalize para a política monetária, equivocadamente, que a taxa de juros tem que aumentar de novo quando, na verdade, a produção corrente está caindo e, portanto, não está pressionando a inflação, mas a taxa de juros derrubou também o produto potencial, ou a oferta, o que não aparece na regra de Taylor. Insistir, nessas condições, no aumento da taxa de juros é inadequado, o que torna discutível a regra de Taylor.

\section{CONSIDERAÇÕES FINAIS}

Retomamos neste artigo uma antiga questão em economia monetária, a da neutralidade ou não neutralidade da moeda, questão que divide até hoje economistas ortodoxos e heterodoxos. Mostramos que ela permanece atual, apesar do chamado novo consenso em política monetária. Isso porque esse argumento aparece na regra de Taylor, regra usada para operar o regime de metas inflacionárias prescrito por tal consenso - em vários países, entre os quais o Brasil.

A crítica feita neste artigo ao regime de metas, mais particularmente à regra de Taylor, destinou-se a mostrar que, se o argumento é o de não neutralidade da moeda, os resultados do uso da regra de Taylor tornam-se discutíveis, porque a operacionalização da política monetária pode envolver resultados ruins em função do efeito inibidor que tem sobre o crescimento da economia e do emprego e porque, a médio prazo, pode comprometer o próprio objetivo almejado de redução da inflação, ao inibir o crescimento da capacidade produtiva.

Segundo a regra de Taylor, que opera o regime de metas inflacionárias, a taxa de juros deve subir sempre que a inflação esperada superar a meta, e sempre que o hiato de produto aparecer ou crescer. Supõe, nesse último caso, que o produto potencial não se altera com o aumento da taxa de juros, que deve, por isso, inibir

\footnotetext{
${ }^{9}$ Observe-se que a escala dos impactos de choques da taxa de juros sobre o hiato é cem vezes menor do que sobre as demais variáveis.
} 
o crescimento do hiato, ou fazê-lo cair, por inibição do crescimento do produto efetivo. Com isso, pressões inflacionárias de demanda seriam evitadas.

Como para os pós-keynesianos a moeda não é neutra, a taxa de juros afeta negativamente o produto potencial, da mesma forma que afeta também o produto efetivo. Uma situação como essa mostra que o regime de metas inflacionárias opera a partir de uma regra, a regra de Taylor, que, apesar de reduzir a inflação, o faz com um custo social muito elevado e desnecessário, porque, além de reduzir a produção corrente e o emprego, ao reduzir o produto potencial, ou a capacidade produtiva da economia, induz desnecessariamente a novos aumentos de juros, tornando a política monetária resistente à sua queda.

Vimos isso por meio dos resultados de dois modelos VAR. No primeiro, destacamos que a taxa de juros não apenas afeta o produto efetivo, como concordam ortodoxos e heterodoxos, mas também o produto potencial, ao contrário do suposto na regra de Taylor, dando razão à heterodoxia.

No segundo VAR, vimos que o teste de causalidade de Granger torna discutível o aumento da taxa de juros para reduzir o hiato de produto, uma vez que não é possível rejeitar a hipótese nula segundo a qual a taxa de juros não causa no sentido de Granger o aumento do hiato de produto. Assim, nossa preocupação é que a leitura equivocada desse resultado leve a outros aumentos da taxa de juros para reagir à resistência do hiato de produto à queda. O equívoco, nesse caso, estaria em que ele não cai porque o produto potencial caiu, e não porque o produto efetivo continua crescendo. Assim, novos aumentos não surtem o efeito desejado, embora tenham um custo social elevado em termos de crescimento e emprego.

Tabela1: Teste de raiz unitária (jul/2000 a set/2008)

\begin{tabular}{|l|c|c|c|c|c|c|}
\hline \multirow{2}{*}{ Variável } & \multirow{2}{*}{ Constante } & \multirow{2}{*}{ Tendência } & \multirow{2}{*}{ Estatística-t } & \multicolumn{2}{|c|}{ valor crítico } & \multirow{2}{*}{ t-prob } \\
\cline { 1 - 3 } IPCA & Sim & Não & $-2,4432$ & $-3,4984$ & $-2,8912$ & 0.1328 \\
SELIC & Sim & Sim & $-3,9896^{*}$ & $-4,0554$ & $-3,4568$ & 0.0121 \\
PIND_EFETIVO & Sim & Sim & $-2,7049$ & $-4,0524$ & $-3,4554$ & 0.2371 \\
POTENCIAL & Não & Não & 2,2256 & $-2,5888$ & $-1,9441$ & 0.9936 \\
D(IPCA) & Não & Não & $-4,1355^{* *}$ & $-2,5888$ & $-1,9441$ & 0.0001 \\
D(SELIC) & Não & Não & $-3,2506 * *$ & $-2,589$ & $-1,9442$ & 0.0014 \\
D(PIND_EFETIVO) & Sim & Não & $-12,2706^{* *}$ & $-3,4977$ & $-2,8909$ & 0.0001 \\
D(POTENCIAL) & Sim & Não & $-13,2654^{* *}$ & $-3,4984$ & $-2,8912$ & 0.0001 \\
\hline
\end{tabular}

* e ** indica significância aos níveis de 1\% e 5\% respectivamente

' $D$ ' indica a primeira diferença da variável

Os valores críticos para a rejeição da hipótese nula da existência de raiz unitária foram gerados pelo pacote econométrico E-views, conforme tabulação desenvolvida em MacKinnon (1991). 
Tabela 2: Seleção do melhor modelo para estimação do VAR

\begin{tabular}{|c|c|c|c|c|c|}
\hline Defasagens & LR & FPE & AIC & SC & HQ \\
\hline 0 & NA & 0.1310 & 9.3194 & 9.4298 & 9.3639 \\
1 & 167.8767 & 0.0264 & 7.7190 & $8.2709^{*}$ & 7.9416 \\
2 & 45.2893 & 0.0216 & 7.5184 & 8.5117 & $7.9191^{*}$ \\
3 & 26.9245 & 0.0219 & 7.5248 & 8.9596 & 8.1037 \\
4 & 33.0304 & $0.0201^{*}$ & $7.4301^{*}$ & 9.3064 & 8.1871 \\
5 & 10.0493 & 0.0252 & 7.6382 & 9.9559 & 8.5732 \\
6 & 14.2034 & 0.0296 & 7.7746 & 10.533 & 8.8878 \\
7 & 9.4497 & 0.0374 & 7.9739 & 11.174 & 9.2651 \\
\hline
\end{tabular}

Variáveis: D(IPCA), D(PIND_EFETIVO), D(POTENCIAL), D(SELIC)

Dados: Julho / 2000 a Setembro/ 2008

Tabela 3: Teste de causalidade no sentido de Granger

\begin{tabular}{|c|c|}
\hline \multicolumn{2}{|c|}{ Variável dependente: D(IPCA) } \\
\hline Hipótese Nula & Probabilidade \\
\hline D(PIND_EFETIVO) não causa, no sentido de Granger, D(IPCA) & 0.0019 \\
\hline D(POTENCIAL) não causa, no sentido de Granger, D(IPCA) & 0.0015 \\
\hline D(SELIC) não causa, no sentido de Granger, D(IPCA) & 0.0000 \\
\hline
\end{tabular}

Tabela 4: Decomposição da variância - D(IPCA)

\begin{tabular}{|ccccc|}
\hline Período & D(IPCA) & D(PIND_EFETIVO) & D(POTENCIAL) & D(SELIC) \\
\hline 1 & 100.0000 & 0.000000 & 0.000000 & 0.000000 \\
5 & 55.67124 & 0.779392 & 5.606737 & 37.94263 \\
10 & 49.44143 & 1.130972 & 5.430509 & 43.99709 \\
12 & 48.44403 & 1.160348 & 5.679458 & 44.71616 \\
\hline
\end{tabular}

Tabela 5: Teste de causalidade no sentido de Granger

\begin{tabular}{|l|l|}
\hline \multicolumn{2}{|c|}{ Variável dependente: D(PIND_EFETIVO) } \\
\hline \multicolumn{1}{|c|}{ Hipótese Nula } & \multicolumn{2}{c|}{ Probabilidade } \\
\hline D(IPCA) não causa, no sentido de Granger, D(PIND_EFETIVO) & 0.3800 \\
D(POTENCIAL) não causa, no sentido de Granger, D(PIND_EFETIVO) & 0.0959 \\
D(SELIC) não causa, no sentido de Granger, D(PIND_EFETIVO) & 0.0014 \\
\hline
\end{tabular}

Tabela 6: Decomposição da variância - D(PIND_EFETIVO)

\begin{tabular}{|lllll|}
\hline Período & D(IPCA) & D(PIND_EFETIVO) & D(POTENCIAL) & D(SELIC) \\
\hline 1 & 0.128213 & 99.87179 & 0.000000 & 0.000000 \\
5 & 2.982829 & 83.14331 & 5.953148 & 7.920713 \\
10 & 4.302015 & 81.54246 & 6.155152 & 8.000372 \\
12 & 4.313700 & 81.49751 & 6.156729 & 8.032064 \\
\hline
\end{tabular}


Tabela 7: Teste de causalidade no sentido de Granger

\begin{tabular}{|c|c|}
\hline \multicolumn{2}{|c|}{ Variável dependente: $\mathrm{D}$ (POTENCIAL) } \\
\hline Hipótese Nula & Probabilidade \\
\hline D(IPCA) não causa, no sentido de Granger, D(POTENCIAL) & 0.1398 \\
\hline D(PIND_EFETIVO) não causa, no sentido de Granger, D(POTENCIAL) & 0.3795 \\
\hline D(SELIC) não causa, no sentido de Granger, D(POTENCIAL) & 0.0012 \\
\hline
\end{tabular}

Tabela 8: Decomposição da variância - D(POTENCIAL)

\begin{tabular}{|ccccc|}
\hline Período & D(IPCA) & D(PIND_EFETIVO) & D(POTENCIAL) & D(SELIC) \\
\hline 1 & 0.252764 & 87.33728 & 12.40995 & 0.000000 \\
5 & 3.091967 & 71.62664 & 15.46170 & 9.819689 \\
10 & 3.657244 & 70.71837 & 15.72219 & 9.902196 \\
12 & 3.657125 & 70.72362 & 15.71962 & 9.899639 \\
\hline
\end{tabular}

Tabela 9: Teste de causalidade no sentido de Granger

\begin{tabular}{|c|c|}
\hline \multicolumn{2}{|c|}{ Variável dependente: D(SELIC) } \\
\hline Hipótese Nula & Probabilidade \\
\hline D(IPCA) não causa, no sentido de Granger, D(SELIC) & 0.0008 \\
\hline D(PIND_EFETIVO) não causa, no sentido de Granger, D(SELIC) & 0.9133 \\
\hline D(POTENCIAL) não causa, no sentido de Granger, D(SELIC) & 0.8107 \\
\hline
\end{tabular}

Tabela 10: Decomposição da variância - D(SELIC)

\begin{tabular}{|ccccc|}
\hline Período & D(IPCA) & D(PIND_EFETIVO) & D(POTENCIAL) & D(SELIC) \\
\hline 1 & 0.042011 & 0.378185 & 0.990479 & 98.58932 \\
5 & 13.82504 & 2.842842 & 2.156929 & 81.17519 \\
10 & 16.94694 & 3.346322 & 4.454542 & 75.25220 \\
12 & 16.99368 & 3.342999 & 4.605908 & 75.05741 \\
\hline
\end{tabular}

Figura 1: Funções Impulso-Resposta - Choques na taxa de juros

Response to Cholesky One S.D. Innovations \pm 2 S.E.
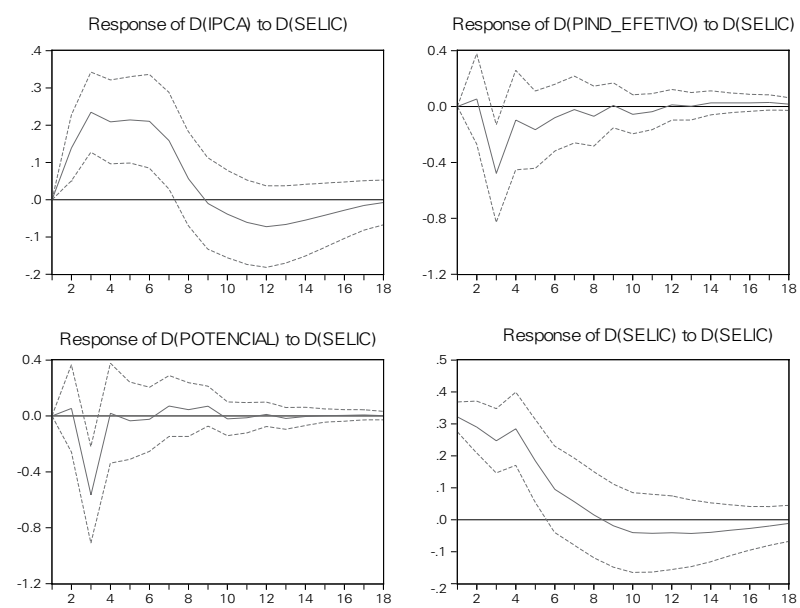
Figura 2: Funções Impulso-Resposta acumuladas - Choques na taxa de juros (Selic)

Accumulated Response to Cholesky One S.D. Innovations \pm 2 S.E.

Accumulated Response of D(IPCA) to D(SELIC)

Accumulated Response of D(PIND_EFETIVO) to D(SELIC
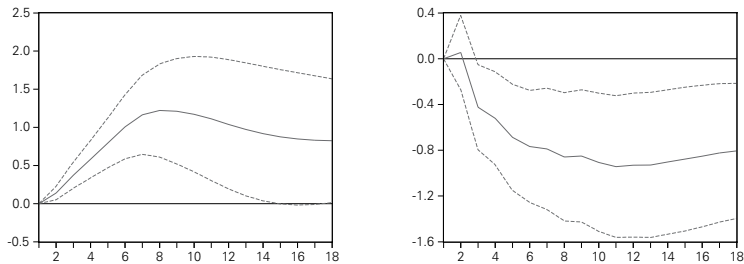

Accumulated Response of D(POTENCIAL) to D(SELIC)
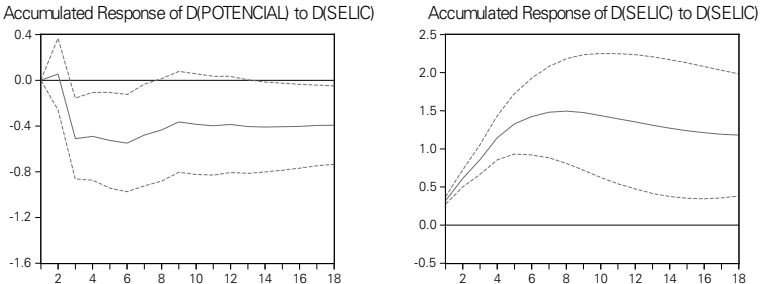

Tabela 11: Teste de raiz unitária (jul/2000 a set/2008)

\begin{tabular}{|c|c|c|c|c|c|c|}
\hline \multirow{2}{*}{ Variável } & \multirow{2}{*}{ Constante } & \multirow{2}{*}{ tendência } & \multirow{2}{*}{ Estatística-t } & \multicolumn{2}{|c|}{ valor crítico } & \multirow{2}{*}{ t-prob } \\
\cline { 5 - 6 } & & & & $1 \%$ & $5 \%$ & \\
\hline HIATO_SA & $\operatorname{Sim}$ & Não & -1.3321 & -3.4977 & -2.8909 & 0.6121 \\
\hline D(HIATO_SA) & Sim & Não & -10.2825 & -3.4984 & -2.8912 & 0.0000 \\
\hline
\end{tabular}

${ }^{*} e^{* *}$ indica significância aos níveis de $1 \%$ e $5 \%$ respectivamente

' $D$ ' indica a primeira diferença da variável

Os valores críticos para a rejeição da hipótese nula da existência de raiz unitária foram gerados pelo pacote econométrico E-views, conforme tabulação desenvolvida em MacKinnon (1991).

Tabela 12: Seleção do melhor modelo para estimação do VAR

\begin{tabular}{|c|c|c|c|c|c|}
\hline Defasagens & LR & FPE & AIC & SC & HQ \\
\hline 0 & NA & $4.07 \mathrm{E}-06$ & -3.8972 & -3.8144 & -3.8638 \\
1 & 159.0373 & $7.98 \mathrm{E}-07$ & -5.5274 & $-5.1963^{*}$ & -5.3939 \\
2 & 28.7486 & $6.91 \mathrm{E}-07$ & -5.6719 & -5.0924 & $-5.4381^{*}$ \\
3 & 16.0750 & $6.92 \mathrm{E}-07$ & -5.6725 & -4.8448 & -5.3386 \\
4 & 24.5056 & $6.18 \mathrm{e}-07^{*}$ & $-5.7889^{*}$ & -4.7128 & -5.3548 \\
5 & 10.5494 & $6.58 \mathrm{E}-07$ & -5.7318 & -4.4074 & -5.1974 \\
6 & 7.9863 & $7.23 \mathrm{E}-07$ & -5.6449 & -4.0721 & -5.0104 \\
7 & 5.4176 & $8.23 \mathrm{E}-07$ & -5.5256 & -3.7045 & -4.7909 \\
8 & $18.2126^{*}$ & $7.72 \mathrm{E}-07$ & -5.6037 & -3.5344 & -4.7689 \\
\hline
\end{tabular}

Variáveis: D(IPCA), D(IPCA) D((HIATO_SA)

Dados: Julho / 2000 a Setembro/ 2008 
Tabela 13: Teste de causalidade no sentido de Granger

\begin{tabular}{|c|c|}
\hline \multicolumn{2}{|c|}{ Variável dependente: D(IPCA) } \\
\hline Hipótese Nula & Probabilidade \\
\hline D(HIATO_SA) não causa, no sentido de Granger, D(IPCA) & 0.0012 \\
D(SELIC) não causa, no sentido de Granger, D(IPCA) & 0.0000 \\
\hline
\end{tabular}

Tabela 14: Decomposição da variância - D(IPCA)

\begin{tabular}{|cccc|}
\hline Período & D(IPCA) & D(HIATO_SA $)$ & D(SELIC) \\
\hline 1 & 100.0000 & 0.000000 & 0.000000 \\
5 & 57.91355 & 6.059122 & 36.02733 \\
10 & 52.97843 & 5.913315 & 41.10825 \\
12 & 51.98677 & 6.156622 & 41.85660 \\
\hline
\end{tabular}

Tabela 15: Teste de causalidade no sentido de Granger

\begin{tabular}{|c|c|}
\hline \multicolumn{2}{|c|}{ Tabela 16: Variável dependente: D(SELIC) } \\
\hline \multicolumn{1}{|c|}{ Hipótese Nula } & Probabilidade \\
\hline D(IPCA) não causa, no sentido de Granger, D(SELIC) & 0.0003 \\
D(HIATO_SA) não causa, no sentido de Granger, D(SELIC) & 0.9498 \\
\hline
\end{tabular}

Tabela 16: Decomposição da variância - D(SELIC)

\begin{tabular}{|cccc|}
\hline Período & D(IPCA) & D(HIATO_SA) & D(SELIC) \\
\hline 1 & 0.004254 & 1.533606 & 98.46214 \\
5 & 16.66932 & 1.208647 & 82.12203 \\
10 & 19.53185 & 3.190174 & 77.27798 \\
12 & 19.45949 & 3.335994 & 77.20452 \\
\hline
\end{tabular}

Tabela 17: Teste de causalidade no sentido de Granger

\begin{tabular}{|l|c|}
\hline \multicolumn{2}{|c|}{ Variável dependente: D(HIATO_SA) } \\
\hline Hipótese Nula & Probabilidade \\
\hline D(IPCA) não causa, no sentido de Granger, D(HIATO_SA) & 0.0798 \\
D(SELIC) não causa, no sentido de Granger, D(HIATO_SA) & 0.1445 \\
\hline
\end{tabular}

Tabela 18: Decomposição da variância - D(HIATO_SA)

\begin{tabular}{|cccc|}
\hline Período & D(IPCA) & D(HIATO_SA) & D(SELIC) \\
\hline 1 & 1.006660 & 98.99334 & 0.000000 \\
5 & 10.03685 & 80.91202 & 9.051131 \\
10 & 12.00906 & 72.83837 & 15.15258 \\
12 & 12.14358 & 72.69983 & 15.15660 \\
\hline
\end{tabular}


Figura 3: Funções Impulso-Resposta - Choques na taxa de juros

Response to Cholesky One S.D. Innovations \pm 2 S.E.

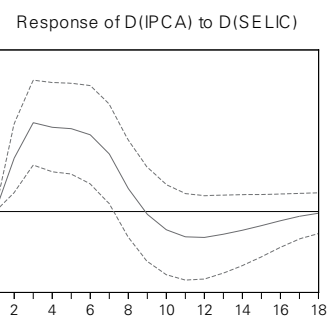

Response of D(HIATO_SA) to D(SELIC)

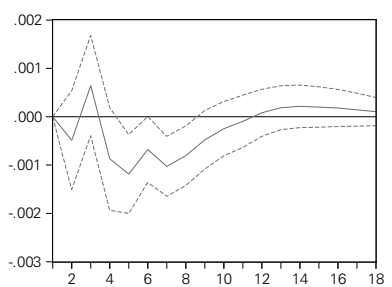

Response of D(SELIC) to D(SELIC)

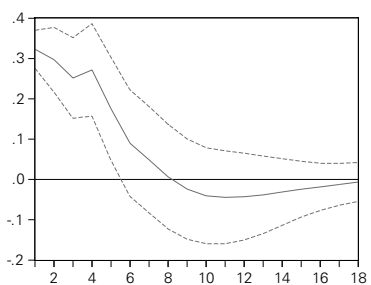

Figura 4: Funções Impulso-Resposta acumuladas - Choques na taxa de juros (Selic)

Accumulated Response to Cholesky One S.D. Innovations \pm 2 S.E.

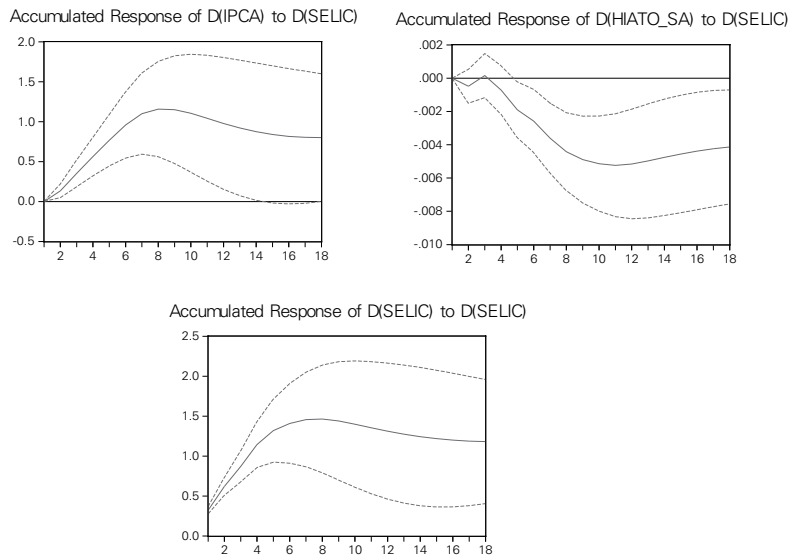

\section{REFERÊNCIAS BIBLIOGRÁFICAS}

ARESTIS, P. e SAWYER, M. (2003). "Inflation targeting: A critical appraisal”. Working Paper Series, Annandale-on-Hudson, Nova York: The Levy Economics Institute, n. 388.

ARESTIS, P. e SAWYER, M. (2005). “New consensus monetary policy: An appraisal”. In: P. Arestis, M. Baddeley \& J. McCombie (eds.) The New Monetary Policy. Chaltenham: Edward Elgar.

BERNANKE, Ben S.; LAUBACH, Thomas; MISHKIN, Frederic S. e POSEN, Adam S. (1999). Inflation Targeting:Lessons from the International Experience. Princeton, NJ: Princeton University Press. 
CUKIERMAN, A.(1994). “Central bank independence and monetary control.” The Economic Journal 104 (November): 1437-1448.

DAVIDSON, P. (1994). Post Keynesian Macroeconomic Theory. Cheltenhan: Edward Elgar.

Davidson, R. e MacKinnon, J. G. (1993). Estimation andIinference in Econometrics. New York, Oxford University Press.

Enders, W. (2004). Applied Econometric Time Series, Wiley.

FEIJÓ, C. A. (2006). "A medida de utilização de capacidade: conceitos e metodologias". Revista de Economia Contemporânea, v. 10, pp. 611-629.

FRIEDMAN, M. (1956). “The quantity theory of money - a restatement”. In: Friedman, M. (org.), Studies in the Quantity Theory of Money, pp. 3-21, Chicago: University of Chicago Press.

GALÍ, J. (2008). “Monetary policy design in the basic new Keynesian model”. In: Galí, J. (org.). Monetary Policy, Inflation, and the Business Cycle: An Introduction to the New Keynesian Framework. Princeton: Princeton University Press.

HERMANN, J. (2003). "Financiamento de longo prazo: revisão do debate e propostas para o Brasil". In: Sicsú, João; Oreiro, José L.; de Paula, Luiz F. (orgs.). Agenda Brasil - Políticas Econômicas para o Crescimento com Estabilidade de Preços. Barueri: Manole/Fundação Konrad Adenauer, pp. 241-293.

IEDI (2006). "Não temer o crescimento econômico". Instituto de Estudos para o Desenvolvimento Industrial”. Carta n. 200, publicada em 24/03/2006.

KANCZUK, F. (2004). "Choques de oferta em modelos de metas inflacionárias”. Revista Brasileira de Economia, Rio de Janeiro, v. 58, n. 4, pp. 559-581.

KEYNES, J. M. (1937a). “Alternative theorieis of the rate of interest”. The Economic Journal (June). (1937b). "Ex-ante theory of the rate of interest", The Collected Writings of John Maynard Keynes, v. XIV, p. 215.

(1937c). “Mr. Keynes' finance”, The Collected Writings of John Maynard Keynes, Vol. XIV, p. 216-235.

KYDLAND, F. e PRESCOTT, E. C. (1977). "Rules rather than discretion: The inconsistency of pptimal plans”. Journal of Political Economy, 85(3), pp. 51-80.

LAIDLER, D. (1971). “The evidence of money on economic activity”. In: Clayton, G.; Gilbert, J. C. e Sedgwick, R. (eds). Monetary Theory and Monetary Policy in the 1970's., Oxford: Oxford University Press.

LAVOIE, M. (1992). Foundations of Post-Keynesian Economic Analysis. England: Edward Elgar.

LUCAS, R. (1972). "Expectations and the neutrality of money". Journal of Economic Theory, v. 4, n. 2, pp. 103-124.

MISHKIN, F. (2000). "What should Central Banks do"? Federal Reserve Bank of St. Louis.

MODENESI, A. (2008). "Convenção e rigidez na política monetária; uma estimativa da função de reação do BCB - 2000-2007”, Texto para Discussão n. 1351, Rio de Janeiro: IPEA.

MOLLO, M.L.R (2004). “Ortodoxia e heterodoxia monetárias: A questão da neutralidade da moeda”. Revista de Economia Política, v. 24, n. 3, pp. 323-343. (1999). "The endogeneity of money". Research in Political Economy, v. 17, pp. 3-26.

OBSTFELD, M. (1998). "The global capital market: Benefactor oar menace?”, paper prepared for Journal of Economic Perspectives.

PALLEY, T. I (2006). "A post Keynesian framework for monetary policy: Why interest rate operating procedures are not enough”. In: Gnos, C., and L.-P. Rochon (eds.), Post Keynesian Principles of Policy. Cheltenham, E. Elgar.

PELICIONI, L. A. \& RESENDE, M. F. C. (2009). "Metas de inflação, política monetária e investimento: um estudo para dezessete países", Revista de Economia Política, v. 29, n. 3(115), pp. 71-92, julho-setembro.

(2006b). "Monetary policy in an endogenous money economy". In Arestis, P. \& Sawyer, M. (eds.). A Handbook of Alternative Monetary Economics. Cheltenham: Edward-Elgar.

PERSON, T. \& G. Tabellini (1993). “Designing institutions for monetary stability.” Carnegie-Rochester Conference Series on Public Policy, v. 39, pp. 53-84. 
RESENDE, M. F. C. \& LIMA, F. (2007). “Metas de inflação e investimento: O caso do Brasil”. São Paulo, Revista da Sociedade Brasileira de Economia Política, n. 21, Dezembro.

ROGOFF, K. (1985). “The optimal degree of commitment to an intermediate monetary target”, Quarterly Journal of Economics, v. C, 1985.

SARGENT, T. J. \& WALLACE, N. (1975). "Rational expectations, the optimal monetary instrument, and the optimal money supply rule". Journal of Political Economy, v. 83, pp. 241-254.

SETTERFIELD, M. (2006). "Is inflation targeting compatible with post Keynesian economics?" Journal of Post Keynesian Economics, v. 28, n. 4, pp. 653-671. , SICSÚ, J. (2002). “Políticas não-monetárias de controle da inflação: Uma abordagem pós-keynesiana”. Anais VII Encontro da Sociedade de Economia Política, Curitiba-PR.

SICSÚ, J. (2003). “Taxa de juros e controle da inflação no Brasil”. In: SICSU, João; Oreiro, José L.; de Paula, Luiz F. (orgs.). Agenda Brasil - Políticas Econômicas para o Crescimento com Estabilidade de Preços. Barueri: Manole/Fundação Konrad Adenauer, pp. 29-64.

SOUZA JÚNIOR, J.R. de C., (2005). "Produto potencial: conceitos, métodos de estimação e aplicação à economia brasileira”. Texto para Discussão 1130, IPEA.

STOCK, J. \& WATSON, M. (2001). "Vector autoregressions". The Journal of Economic Perspectives, v. 15, n. 4.

SVENSSON, L. (2003). "What is wrong with Taylor rules? Using judgment in monetary policy through targeting rules". Journal of Economic Literature, v. 41, n. 2, pp. 426-477.

TAYLOR, J. B. (1993). "Discretion versus policy rules in practice". Carnegie-Rochester Conference Series on Public Policy, v. 39, pp. 195-214, North-Holland.

TAYLOR, J. (1998). “A historical analysis of monetary policy rules”. NBER Working Paper 6768, Cambridge.

WOODFORD, M. (2001). "The Taylor rule and optimal monetary policy”. American Economic Review, v. 91, n. 2, pp. 232-237. (2008). "Convergence in macroeconomics:elements of the new synthesis". Remarks for a panel discussion at the AEA meeting, January 2008; http//www.columbia.edu.

WALSH, C. (1995). “Optimal contracts for central bankers”. American Economic Review, v. 85, n. 1: pp. 150-157.

WRAY, R. (1997). "Deficits, inflation, and monetary policy”. Journal of Post Keynesian Economics, v. $19,4$. 